Foro Interno. Anuario de Teoría Política

ISSN: $1578-4576$

\title{
Deformidad en los mecanismos democráticos
}

\section{[en] Deformity in Democratic Mechanisms}

Entre el ardor patriótico y las teorías románticas que nos articulan la vida, la democracia ha ido coloreándose de muchos tonos y ha adquirido nuevas intenciones. Teniendo en cuenta que respiramos en una sociedad belicosa e inmersos en la lucha por la vida, la emancipación de cada uno de nosotros sólo puede lograrse por dos caminos: (i) adinerándonos o (ii) preponderando (empoderándonos). En palabras tradicionales, la salida está en enriquecerse o dominar.

Recientemente en una culta radio latinoamericana se mencionaba que hoy en día: "la voluntad del pueblo es la voluntad de Dios". La cita es reveladora porque pone al desnudo la religiosidad aberrante que hoy inunda la teoría política. Muchos ya se sienten incómodos con una clase avanzada que, utilizando su ateísmo, se cree dotada para desmontar la brutalidad reaccionaria.

El asunto es que, a medida que adquirimos más conocimientos, nos empezamos a dar cuenta de las preparaciones a las que nos han sometido los ideólogos del altavoz y la corrupción. En cierto modo el denuncismo nos ha despistado y no captamos cómo los vicios despóticos tradicionales se mantienen, aunque transmutados.

Una nota de nuestras repúblicas es que han emergido de situaciones repulsivas de tiranía o, cuando menos, de dictaduras de oligarquías nefastas. Culturas llenas de religiosidad arcaica e incompetencia que sumían a la población en la desgracia cívica y la ruina material. La teoría política del siglo veintiuno no tiene, por tanto, marcha atrás.

\section{Ateos religiosos}

Una de las mayores sorpresas a los auditorios emerge cuando se les comenta que la política actual está llena de ateos piadosos; que vivimos en una época muy religiosa. Nuestros líderes y políticos profesionales abiertos al cambio presumen de laicismo e irreligiosidad, pero el ambiente de las instituciones, las modas, los deportes y el comercio acelerado es intensamente piadoso. ¿Esto qué significa?

Dada tanta piedad, igual que no debe extrañarnos que los mafiosos asesinos casen a sus hijas en las iglesias católicas, tampoco lo debe hacer el respeto reverencial de los nuevos políticos por ciertos axiomas que, de puro irracionales, son impertinentes. Como exclamaba, siempre en ese tono exhortativo de los políticos vigilantes, un profesor universitario en 2016, "el pueblo es Dios".

El fervor incondicional hacia cualquier dios despliega enseguida un santoral de temas y personajes que hay que cuidar y defender. Y así lo hacen estos fieles punteros de la razón y de los avances revolucionarios. Inmediatamente sacan el top-manta y lo extienden en el suelo con todas sus estampitas ideológicas y retratos de sus hé- 
roes. Se mantienen siempre alerta y con cuidado de que nadie se lo pise, porque de eso se mantienen. Se les distingue enseguida por cómo se hablan entre ellos a voces y sin escucharse.

Los políticos románticos, que abundan hoy de todos los colores, se lanzan a defender piadosamente sus ideas y las de sus jefes. Y lo hacen como verdaderos fanes, que eran los encargados de barrer y mantener limpios los templos, las estatuas y las tumbas; y de cambiar las flores de los recintos intocables para mantener la frescura del montaje.

Argumento lo anterior porque empieza a oírse que la corrupción, que hasta ahora era considerada justamente como una perversión del ciudadano debido a prácticas negativas - que se aspiraba a arrancar mediante la acción vigorosa revolucionaria o la constancia transformadora de la educación y la justicia-, no solo no desaparece una vez implantados los remedios, sino que se asienta y fortalece. Y el caso es que ahora está surgiendo una gran perplejidad: ¿cómo es posible que se corrompan las fórmulas democráticas? ¿Es posible que unos procedimientos y unos mecanismos montados para contrarrestar el vicio de la política se muestren ahora contaminados ellos mismos?

\section{Nuevos aires viciados de piedad}

Lo cierto es que los nuevos líderes, que por fin ya sí pueden poner en práctica sus ideas e imponer su arbitrio, empiezan a mostrar una piedad muy rigurosa a la hora de valorar los hechos políticos. Todos ellos siguen siendo apasionados de la lucha okupativa - ocupar los puestos para siempre - y se embadurnan de un narcisismo vulgar y un protagonismo repulsivo. Cuando nos aproximamos a las nuevas instituciones democráticas, volvemos a encontrarnos con la bofetada del oportunismo: el familismo, la mentira sistemática, el respeto al santoral gansteril de los nuestros y la repetición maniática del más brusco partidismo.

La familia, el pegarse a los parientes, las parejas esquizoides, los amigotes, los gustos personales, obedecer ciegamente al jefe, todo eso se llevará al puesto de trabajo, a los grupos sociales y al partido. Y se les promocionará a puestos de responsabilidad estatal. Son el nuevo ropaje para seguir haciendo lo mismo: manipular y controlar en nuestra vida desde los niveles más primarios. Comer y viajar gratis se ha apoderado de las nuevas figuras públicas.

Con mucha sensatez, la ética siempre ha tenido por crucial la formación de un nuevo ciudadano. Tanto la moralidad de la socialdemocracia como la socialista estaban convencidas de que una buena ingeniería constitucional y la implantación de nuevas prácticas iban a generar una novísima generación. Ahora vendrían jóvenes, luego maduros, que no encontrarían sentido a la corrupción pública. Por ejemplo, ¡la entrada en escena y liberación al fin de la mujer! ¡Los privilegios! En este punto la corrupción social, que era para ellos la consecuencia de la educación capitalista o de la putrefacción de las tradiciones burguesas, ya no tendrían razón de ser en la democracia. ¡Adiós a la suciedad de los piropos, a la violencia machista y al enchufismo hasta para llevar a un pariente a operar! Pero..., no está resultando fácil porque, como se queja un vallenato: 
Es evidente que la historia no se ha desarrollado tan dócil como pensaban los demócratas posteriores a las dictaduras. Países en donde ha triunfado la revolución moderna o en donde la democracia se ha implantado, no han logrado hacer desaparecer la corrupción pública, que sigue manando.

Repasando las sociedades contemporáneas, o bien las prácticas de corrupción se mantienen, o bien se ha logrado expulsar de nuestras casas purgando el territorio, en este caso proyectando nuestros vicios y defectos tiránicos sobre el exterior del Estado; una treta que es ahora demasiado visible. Insoportable cuando vemos cómo los países civilizadores y primeros en las clasificaciones de limpieza política mantienen guerras muy violentas y abusivas en su megapolítica.

La ficción de que con las prácticas democráticas se fumigan todas las tentaciones de tiranía ha producido un manojo de términos de ingeniería política algo inquietantes. Se postulan porque promueven una política limpia. Este es el caso de la transparencia en las administraciones, votar a cualquier precio y para todo, el imperio de la ley y la búsqueda de la paz (generalmente se quiere decir el orden público regido por las leyes). Todo suena muy bien.

Pero hoy comienza a plantearse una nueva duda. Los ciudadanos empiezan a ver que, con esos artilugios no se garantiza el desmontaje de la corrupción. Es más, se empieza a sospechar que los mecanismos impecables llegan ellos mismos a veces a corromperse y son usados para el objetivo inverso. Para muchos incluso se está produciendo una incipiente gansterización de la política.

En el interior de los estados, la transparencia, por citar un ejemplo, puede ser en sí dañina o un subterfugio para afianzar más la vigilancia de los poderosos y para que las mafias sigan adelante e incluso con más fuerza y fiereza. Tenemos también otras acciones sagradas como son la emancipación, la autonomía universitaria y la democratización de todos los claustros, las directivas y las juntas, que pueden precisamente servir para ahorcar la libertad. Lamentablemente la democracia vigilante sin letargia empuja el viejo carro en esa dirección: hacia un laberinto repleto de angustia y omnipotencia que aboca a la enfermedad.

Claro que los demócratas piadosos jamás aceptarían eso. Para ellos la democracia es vulnerable precisamente porque es buena en sí y respeta y promueve por encima de todo la libertad. Todo un verdadero dogma que hay que creer por encima de todo.

Pero los adolescentes, las clases sociales normales, los trabajadores sin brillo, la vida fecunda de muchos creadores que no protagonizan gran cosa ni están en panta1la, perciben que esos figurones y esas grandes instituciones les son incompresibles por aburridos y falsos.

Muchos otros que sí se mueven cerca de esas hogueras de las vanidades, y las observan de cerca porque no les queda más remedio, empiezan a ver cómo se hacen las cosas. Aprenden que en las instituciones de la gran cultura como las academias científicas, las universidades, los medios de comunicación y las organizaciones profesionales, es precisamente mediante esas prácticas santas como se han instalado beatíficamente los grupos mafiosos.

De igual manera ocurre con la libertad de prensa. Un instrumento, sin duda importante, resulta que es ahora indispensable para mantener el control sobre la llamada opinión pública, a la que se adula y agita tanto que cualquiera puede sospechar que se la quiere seducir y tener reducida a aparentar que todo va bien. Que las cosas marchan o que, al menos, no va todo lo mal que podría ir en un mundo tan amenazante como el que vivimos. 
En las sociedades democráticas esto es muy relevante. Los grandes partidos y sus financiadores, los personajes más fuertes y maníacamente activos, los grupos de sectores sociales bien trabados para ser eficientes, tendrán todos buen cuidado en poseer sus propios grupos de comunicación, ¡a poder ser consiguiendo que sean sostenibles!

Lo mismo se puede decir de los agentes evaluadores. Los encargados de calibrar la valía de los demás, ¡de convencernos de cuánto valemos cada uno!; es decir, de controlar los tipos de cambio de todo tipo, el valor de las divisas suyas y de los demás, la evaluación del talento de las personas y, si llega el momento, el control de las fábricas de creación de dinero o de los valores científicos, industriales y financieros, quedarán sujetos a su regimentación.

En definitiva, el manejo de las riquezas más nobles del mundo, incluido el ingenio artístico, el coraje cívico o la bondad. ¡Arbitraje incandescente en estado puro! 